\title{
DOS MANERAS DE ENTENDER DEL AMOR: ANDRÉS EL CAPELLÁN FRENTE AL DOCTOR LÓPEZ DE VILLALOBOS
}

\author{
ANÁLISIS COMPARATIVO DEL DE AMORE Y LAS SENTENCIAS SOBRE AMOR
}
TWO WAYS TO UNDERSTAND LOVE: ANDREAS CAPELLANUS VERSUS DR. LÓPEZ DE VILLLALOBOS

a comparative analysis of De Amore and sentences of love

\section{DUAS FORMAS DE COMPREENDER O AMOR: ANDRÉ CAPELÃ VERSUS O DOUTOR LÓPEZ DE VILLALLOBOS}

uma análise comparativa entre De Amore $e$ sentenças de amor

\author{
Sergio Montalvo Mareca \\ (Universidad Complutense de Madrid e Instituto Universitario Menéndez Pidal) \\ e-mail:sergmont@ucm.es
}

Recibido: $29 / 08 / 2021$

Aprobado: 08/12/2021

\begin{abstract}
RESUMEN
Este trabajo analiza la idea del amor como elemento literario y sus implicaciones en el comportamiento humano. Para ello, se han seleccionado dos tratados clásicos que explican el amor en todas sus vertientes, el De amore de Andrés el Capellán (siglo XII) y las Sentencias sobre amor de Francisco López de Villalobos (siglo XVI). A pesar de la diferencia temporal, ambas obras comparten una vinculación inequívoca en cuanto a la forma que los dos autores tienen de entender las características y comportamientos del amor. Entre otros, se trata su origen, los diferentes tipos que existen (esencialmente divididos en buen y mal amor), los grupos sociales que están capacitados para el ejercicio amatorio o los peligros de elegir una mala pareja. Por otro lado, resultan igualmente relevantes para el propósito del artículo las diferencias que se extraen de la comparación intertextual. Mientras que Andrés el Capellán defiende el amor pasional como una consecuencia inevitable de la atracción física entre hombres y mujeres, Villalobos lo interpreta como una enfermedad mental que acaba por destruir al varón, pues termina con un cuadro grave de enajenación que lo empuja a cometer todo tipo de imprudencias. Frente a este, Villalobos aboga por un amor puro y espiritual, libre de cualquier patología, que es el amor a Dios. El Capellán también admite que existen amores nocivos para el alma y el cuerpo (con prostitutas, con monjas...) y explica las consecuencias de su ejercicio para disuadir a quienes pudiesen desearlos.
\end{abstract}

Palabras clave: Amor. Andrés el Capellán. De amore. Villalobos. Sexualidad.

\section{ABSTRACT}

This paper analyzes the idea of love as a literary element and its implications in human behavior. Two classic treatises have been selected that explain love in all its aspects, the $D e$ amore by Andreas Capellanus (12 ${ }^{\text {th }}$ century) and the Sentencias sobre amor by Francisco de 
Villalobos $\left(16^{\text {th }}\right.$ century). Despite the time difference, both texts share an unequivocal link in terms of the way the two authors understand the characteristics and behaviors of love. They explain its origin, the different types that exist (essentially divided into good and bad love), the social groups that are qualified for the exercise of love or the dangers of choosing bad lovers. On the other hand, the differences drawn from the intertextual comparison are equally relevant for the purpose of the article. While Andreas Capellanus defends passionate love as an inevitable consequence of the physical attraction between men and women, Villalobos interprets it as a mental illness that ends up destroying the man, since he ends up with a serious state of alienation that pushes him to commit all kinds of imprudence. Villalobos advocates a pure and spiritual love, free of any pathology, which is the love of God. Andreas Capellanus also admits that there are loves harmful to the soul and body (with prostitutes, with nuns...) and explains the consequences of their exercise to dissuade those who might desire them.

Keywords: Love. Andreas Capellanus. De amore. Villalobos. Sexuality.

\section{RESUMO}

Este artigo analisa a ideia do amor como elemento literário e as suas implicações para o comportamento humano. Para este fim, foram selecionados dois tratados clássicos que explicam o amor em todos os seus aspectos, o De amore de André Capelão (século XI) e o Sentencias sobre amor de Francisco de Villalobos (século XVI). Apesar da diferença temporal, as duas obras partilham uma ligação inequívoca em termos da compreensão dos dois autores das características e do comportamento do amor. Entre outras coisas, os autores escrevem sobre a sua origem, os diferentes tipos que existem (essencialmente divididos em bom e mau amor), os grupos sociais capazes de fazer amor e os perigos de escolher maus amantes. Por outro lado, as diferenças que podem ser extraídas da comparação intertextual são igualmente relevantes para o objetivo do artigo. André Capelão define o amor apaixonado como uma consequência inevitável da atracção física entre homens e mulheres. Villalobos, por outro lado, interpreta-o como uma doença mental que acaba por destruir o homem, uma vez que ele acaba com um sério estado de alienação que o leva a cometer todo o tipo de imprudência. Contra isto, Villalobos defende um amor puro e espiritual, livre de qualquer patologia, que é o amor de Deus. O Capelão também admite que existem amores que são prejudiciais à alma e ao corpo (com prostitutas, com freiras...) e explica as consequências do seu exercício, a fim de dissuadir aqueles que os possam desejar.

Palavras-chave: Amor. André Capelão. De Amore. Villalobos. Sexualidade.

\section{Introducción}

Elaborar un recorrido que dé cuenta de las diferentes perspectivas por las que ha pasado el sentimiento amoroso a lo largo de la historia resultaría una tarea imposible. No obstante, durante los últimos siglos de la Edad Media despuntó un modelo que introdujo una nueva manera de amar —al menos desde el punto de vista literario - . Es necesario remontarse hasta el sur de Francia, a las regiones de Provenza y Aquitania, durante los siglos XI-XIII. Allí se considera que se originó lo que Gaston Paris bautizó como amour courtois (1883) ${ }^{1}$.

El primer testimonio de este trabajo, el De amore de Andrés el Capellán, se escribió en torno a 1185 y supone la recopilación de todas las características y preceptos que se encuentran en el código del amor

\footnotetext{
${ }^{1}$ Este artículo no pretende ocuparse del estudio del amor cortés ni tampoco de la revisión de toda la bibliografía existente en torno a este tema. Para ello, se aconseja la lectura de Parker (1986), Rodazo (2000) y del recopilatorio elaborado por Basarte (2012), que reúne los estudios clásicos de Duby, Burnley o Huizinga, entre otros.
} 
cortés. La obra presenta una división en tres libros, emulando el Ars Amandi de Ovidio ${ }^{2}$. En el primero se tratan los aspectos formales del amor: sus efectos, los sujetos que pueden sentirlo, las características de los buenos amantes o los distintos métodos para lograrlo. El segundo libro se ocupa de abordar las claves necesarias para, una vez logrado, conservarlo y aumentarlo. Por último, en el tercero, que lleva el nombre de Reprobatio, el religioso se retracta de lo expuesto hasta entonces.

La segunda obra, las Sentencias sobre amor del doctor Francisco López de Villalobos (1473-1549) posee un interés añadido, pues es fruto de la reflexión de un médico. Este texto breve aparece como colofón de un volumen misceláneo, comúnmente bautizado como Problemas e impreso en Zamora en 1543. En él, el polígrafo renacentista aborda una serie de cuestiones médicas y físicas (los mencionados Problemas), e incluye otros textos, como dos diálogos sobre medicina, una traducción del Anfitrión de Plauto o las estas Sentencias (Rojo Vega, 1993: 184-185). Villalobos ofrece una concepción del amor atípica, pues compara el sentimiento con una enfermedad cerebral que termina por afectar gravemente a los individuos que la padecen. Con todo, no es una novedad, pues las interconexiones entre el mundo erótico y el patológico se remontan, al menos, al siglo $\mathrm{V}$ a.C. como se extrae de los textos de Platón, Aristóteles o Hipócrates (Cabello Pino, 2012). Tampoco resulta inverosímil encontrar algunas ideas paralelas en el De amore. Entre las precisiones sobre el amor cortés de Andrés el Capellán aparecen citados aspectos como la imposibilidad de que exista el amor si no existen los celos o el estado de desconfianza permanente al que está sometido el amante durante la fase de enamoramiento-enajenación; dos realidades que, desde un enfoque clínico, pueden enraizarse con un trastorno de obsesión paranoide (López Paredes y Orellana, 2013: 27). De la misma manera se describen otros comportamientos de la fase de enamoramiento que son próximos a las manifestaciones sintomáticas que muestra el cuerpo humano ante la enfermedad. Estas son, por ejemplo, falta de apetito, insomnio, disminución del estado de vigilia o irritabilidad, entre otras.

\section{Análisis del concepto de amor}

La definición del amor, así como de sus procesos, partes o resultados es una preocupación intrínseca del ser humano. Supone el tema literario protagonista de cualquier época y, a través de los textos, es posible analizar los distintos aspectos que lo conforman. En las dos obras que aquí se tratan se aporta un estudio concienzudo y minucioso sobre el ejercicio de amar. A pesar de que tanto el De amore como las Sentencias sobre amor se enmarcan en el género tratadístico, ambas comparten una redacción dinámica, bien estructurada y fundamentada sobre el componente práctico. Los argumentos se exponen siguiendo un esquema de pregunta-respuesta, implícito en el caso de Villalobos y explícito en el de Andrés el Capellán: ¿qué es el amor?, ¿cómo surge?, ¿entre quiénes puede darse?, ¿qué provoca en ellos?, etcétera.

Para Andrés el Capellán, el amor equivale a la pasión carnal y es una cualidad inherente del ser humano. Además, está relacionado con la percepción de la belleza, es decir, con la atracción: "amor est passio quaedam innata procedens ex visione immoderata cogitatione forme alterius sexus, ob quam aliquis super omnia cupit alterius potiri amplexibus et omnia de utriusque voluntae in ipsius amplexu amoris praecepta compleri” (Capellán, 1985:54) ${ }^{4}$. Como es algo innato, no es sensible de planificación o nacimiento voluntario, sino que se manifiesta en respuesta ante algún estímulo captado por la vista. Aquí se introduce otra matización. Si bien el sentimiento amoroso surge a partir de la visión, además es necesario que sufra una fase de reflexión en la que el amante enloquezca poco a poco por poseer el cuerpo que lo atrajo:

Quod autem illa passio sit innata, manifesta tibi ratione ostendo, quia passio illa ex nulla oritur actione subtiliter veritate inspecta; sed ex sola cogitatione quam concipit animus ex eo quod vidit passio illa

\footnotetext{
${ }^{2}$ Para el análisis de la influencia ovidiana en el De amore, se recomienda acudir a Martínez Sáez (2020).

${ }^{3}$ Sobre Villalobos, véanse los trabajos de Fabié (1886a y 1886b), la actualización de Sánchez Granjel (1979) y otros trabajos breves: Arrizabalaga (2002) y Baranda Leturio (2014).

${ }^{4}$ Se ha decidido usar la edición bilingüe latín-castellano de Creixell Vidal-Quadras y, dentro de esta, la parte latina. Esta decisión tiene su fundamento en la versión menos rica terminológicamente que ofrece la traducción castellana respecto al texto latino. Con el mismo criterio se ha preferido tal edición a otras de buen rigor filológico, como las de Walsh (1982) o Rodríguez (2006). Asimismo, de ahora en adelante se citará de manera abreviada solo con el número de página entre paréntesis.
} 
procedit.Nam quum aliquis videt aliquam aptam amori et suo formatam arbitrio, statim eam incipit concupiscere corde; postea vero quotiens de ipsa cogitat, totiens eius magis ardescit amore, quousque ad cogitationem devenerit pleniorem. Postmodum mulieris incipit cogitare facturas, et eius distinguere membra suosque actus imaginari eiusque corporis secreta rimari ac cuiusque membri officio desiderat perpotiri (56).

De acuerdo con esto, para el religioso todas aquellas emociones que no provocan cierta obsesión no pueden llamarse amor: "Non quaelibet cogitatio sufficit ad amoris originem, sed immoderata exigitur; nam cogitatio moderata non solet ad mentem redire, et ideo ex ea non potest amor oriri" (54). De hecho, en la propia etimología de la palabra, según el autor, ya se aportan estas características. Como señala la editora, dicha teoría procede de la identificación de amare con hamare ('coger con el anzuelo', en latín), relación que ya aparece en las Etimologías de Isidoro de Sevilla (X, L, 5). Así, el enamorado es una especie de pez metafórico que muerde el anzuelo de la pasión. A la vez, él es también el pescador que, con sus cebos, pretende pescar la mujer para poseerla:

UNDE DICATUR AMOR. Dicitur autem amor ab amo verbo, quod significat capere vel capi. Nam qui amat captus est cupidinis vinculis aliumque desiderat suo capere hamo. Sicut enim piscator astutus suis conatur cibiculis attrahere pisces et ipsos sui hami capere unco, ita vero captus amore suis nititur alium attrahere blandimentis, totisque nisibus instat duo diversa quodam incorporali vinculo corda unire, vel unita semper coniuncta servare (62).

Por su parte, Villalobos en su concepción sobre los inicios del estado de enamoramiento abandona el componente sexual para centrarse en el platónico:

El amor es una donación que se da, porque a quien tú amas ofrécesle y dasle tu amor; y éste daslo de tu voluntad, que ninguno ama por fuerça. La voluntad no tiene mayor cosa que pueda dar que el amor, porque es dar su querer y darse a si misma. Siguese d'aqui que a quien tu amas dasle tu voluntad. Y por quanto tu voluntad es tu senora, a quien tu sirves y por quien te mueves y te riges, siguese que a quien das tu voluntad le das a ti mismo. Pues luego el amor es una donación que el amante haze a la cosa amada, en la qual le ofrece y trespassa su voluntad con todas las cosas que a la voluntad pertenescen (Villalobos, 2001:223$224)^{5}$.

De lo anterior se extrae que el varón que se entrega en amor a la amada ya no es dueño de sí, pues la propiedad la ejerce su señora. No obstante, para que el amor sea bueno y verdadero es necesario que la parte contraria done también su voluntad, solo así los dos estarán plenamente constituidos, aunque con las voluntades intercambiadas: "De manera que ya tú no te puedes mover ni governar por tu voluntad, pues no la tienes; ni puedes tener otra condición ni otro querer mas del que tiene la cosa que amas, porque en ella lo enajenaste todo y eres miembro suyo. Por esto dizen que el amante se trasforma en el amado" (224). A continuación, el médico distingue dos tipos de amor: el verdadero, que se tratará más adelante, y el vicioso, que no es otro que aquel que busca obtener un placer carnal por encima del beneficio espiritual. Este falso amor se caracteriza por una pasión desmedida por poseer a la dama.

Asimismo, el Capellán advierte que el amor solo puede existir entre personas de diferente sexo, pues, de lo contrario, no existe una disposición natural del cuerpo para otras prácticas: "duae namque sexus eiusdem personae nullatenus aptae videntur ad mutuas sibi vices reddendas amoris vel eius naturales actus exercendos" (58). De nuevo, responde a un criterio puramente sexual porque lo que el amante busca en el amor es, en definitiva, gozar de su amada. Muchas veces, el deseo por alcanzar el premio de la carne es tan desmedido que lleva a los hombres a cometer acciones imprudentes que, con el tiempo, terminan por debilitar el sentimiento y hasta su propia salud: "Videmus enim ipsos mortem contemnere nullasque timere minas, divitias spargere et ad multas devenire inopias" (60).

Para Villalobos, el falso amor también está estrictamente ligado al sexo. Quienes lo practican no se guían por sentimientos honestos, sino que se mueven por la sed de hallar un momento de deleite sexual. Heredando la terminología aristotélica, el doctor dice que este es un comportamiento impropio de los

\footnotetext{
${ }^{5}$ Como en el caso anterior, en lo sucesivo se citará de manera abreviada.
} 
hombres buenos, pues responde a las necesidades del alma sensitiva. Por ende, lo correcto es que el amor permita el desarrollo de las capacidades del alma intelectiva, solo entonces puede ser bueno:

Provado está assimismo que el amante se convierte y transforma em la cosa amada; síguese qu'el amador se torna de la condición y naturaleza daquel deleite que ama. Éste no es deleite de hombre en quanto es hombre, porque no consiste en la razón y entendimiento, que es lo que haze al hombre ser hombre, difirente de los brutos, mas consiste en los sentidos corporales, que son dados prinicipalmente a las bestias, porque su perfición es el ánima sensitiva, por la qual son animales. De aquí se sigue que los deleites sensitivos pertenecen a las bestias por parte de las bestias (227).

La siguiente noción que presenta el Capellán es la de los colectivos que están capacitados para introducirse en el amor, pues no todos los seres humanos están preparados para este noble arte. Comienza enunciando aquellos grupos que no pueden o no deben acceder. La edad hábil para amar es algo que preocupa a los dos autores. Ya se verá como Villalobos considera que quienes peinan canas ya deben abandonar este ejercicio. Tal preocupación provoca que el primero de los grupos que trata el Capellán sea el de los ancianos, donde engloba a los hombres con más de cincuenta años y a las mujeres de más de sesenta. El autor recomienda a los varones de esta edad se entreguen a otros placeres, como los de la comida o el vino, pues; además, les desaconseja continuar manteniendo relaciones sexuales ya que podrá provocarles molestias físicas:

\begin{abstract}
Aetas impedit, quia post sexagesimum annum in masculo et post quinquagesimum in femina, licet coire horno possit, eius tamen voluptas ad amorem deduci non potest, quia calor naturalis ab ea aetate suas incipit amittere vires, et humíditas sua validissime ínchoat incrementa fovere, atque homínem in varias deducit angustias et aegritudinum diversarum molestat insidiis, nullaque sunt sibi in hoc saeculo praeter cibi et potus solatia (66).
\end{abstract}

Tampoco el religioso evalúa la excesiva juventud como buena compañera para lograr el amor correcto. En esta línea, precisa que las mujeres no deben empezar a amar antes de los doce años ni los hombres hasta los catorce puesto que, si bien el varón a la edad de catorce años dispone de plenas facultades viriles (entiéndase capacidad eréctil y fértil), no será un buen amador hasta que alcance los dieciocho, edad a la que el autor juzga que maduran socialmente los varones:

\begin{abstract}
Dico tamen et firmiter assero quod masculus ante decimum octavum annum verus esse non potest amans, quia usque ad id tempus pro re satis modica verecundo rubore perfunditur, qui non solum perficiendum impedit amorem sed bene perfectum exstinguit. Sed et alía ratio efficacior invenitur, quia ante praefatum tempus nulla in homíne constantia viget, sed in omnibus varíabilis reperitur. Nec enim aetatis de amoris imperíi arcanis posset tanta infirmitas cogitare (66).
\end{abstract}

El tercer colectivo que Andrés el Capellán considera que debe abstenerse de iniciarse en los juegos del amor son los viciosos. En este caso, se refiere solo al sexo masculino, aunque en otra parte de su tratado hablará de las mujeres viciosas. Los varones viciosos aparecen presentados como seres insaciables que ansían yacer con el mayor número de mujeres posible y que son incapaces de desarrollar ningún tipo de vínculo hacia ninguna de ellas ya que su objetivo es solo el de procurar el placer. De este modo, en ellos nunca podrá existir un sentimiento real más que el desfogue:

\footnotetext{
Nimia voluptatis abundantia impedir amorem, quia sunt quidamqui tanta voluptatis cupidine detinentur quod amoris non possunt retineri reticulis; qui post multas etiam de muliere cogitationes habitas vel fructus assumptos, postquam aliam vident statim illius concupiscunt amplexus, et obsequii a priore amante suscepti obliviosi et ingrati exsistunt. Illi tales quot vident tot cupiunt libidini immisceri. Istorum talis amor est qualis est canis impudici. Sed nos credimus asinis comparandos; ea namque solummodo natura moventur guae ceteris animantibus homines ostendit aequales, non vera quae rationis differentia nos a cunctis facit animalibus separari (68).
}

Villalobos también advierte de los peligros de ser un hombre vicioso. En cambio, para él, no lo es quien busca insaciablemente mujeres con las que gozar, sino, sencillamente, aquel que renuncia al amor espiritual por la lujuria. Para amar, es necesario entregar la voluntad a la amada, de manera que el hombre pierde su estatus superior masculino para convertirse en una parte todo lo que antes era. Como 
consecuencia de haberse donado a la mujer y de haber renunciado al verdadero amor, el varón experimentará una serie de sensaciones como la debilidad o la tristeza sin saber de dónde proceden. Esto supondrá una penitencia eterna a pagar por haberse entregado a la concupiscencia:

\begin{abstract}
Mira qué tan grande es tu pérdida en semejantes amores que, como tu voluntad y lo que ella señorea posee la muger que amas y tú no, síguese que te perdiste a ti mismo y dexaste de ser. Assí que tú no eres ya quien eras, mas aste trocado por outra cosa muy desigual em valor y muy lexos de lo que antes eras, ca dexaste de ser hombre y tórnaste mujer, dexaste de ser hombre suelto y libre y házeste muger cativa y atada; dexaste de ser todo y tórnaste parte. Y ya sabes que toda muger dessea ser hombre y todo esclavo desea ser libre, y la parte desea la perfición del todo, assí que tu desearás todas estas cosas (225-226).
\end{abstract}

Tanto el Capellán como el doctor Villalobos reconocen el poder perfeccionador que tiene el amor cuando es bueno, pues logra engrandecer a quien lo profesa. La visión de Andrés el Capellán comulga con la idea neoplatónica de mejora de los individuos y de acercamiento a la perfección. Cuando el hombre ama, se perfecciona y adquiere nuevas virtudes. Además, aporta una cualidad adicional: la castidad, entendida como fidelidad. Esta hace que el enamorado no advierta los encantos de ninguna otra mujer que no sea la suya:

\begin{abstract}
Effectus autem amoris hic est, quia verus amator nulla posset avaritia offuscari; amor horridum et incultum omni facit formositate pollere, infimos natu etiam morum novit nobilitate ditare, superbos quoque solet humilitate beare; obsequia cunctis amorosus multa consuevit decenter parare. O, quam mira res est amor, qui tantis facit hominem fulgere virtutibus, tantisque docet quemlibet bonis moribus abundare! Est et aliud quiddam in amo re non brevi sermone laudandum, quia amor reddit hominem castitatis quasi virtute decoratum, quia vix posset de alterius etiam formosae cogitare amplexu, qui unius radio fulget amoris. Est enim suae mentí, dum de amore suo plenarie cogitat, mulieris cuiuslibet horridus et incultus aspectus (64).
\end{abstract}

La teoría de Villalobos, en cambio, está más vinculada a la religión, pues, a pesar de las numerosas indicaciones que aporta el médico zamorano sobre las relaciones interpersonales, será el amor entre el ser humano y Dios el único que admita como legítimo y perfecto, mientras que el resto, aunque lícitos en algunos casos, siempre se encontrarán manchados. Así, frente al amor ferinus, que conducía al alma sensitiva, este amor divino libera al alma de todo lo terrenal y la eleva al cielo, junto a su enamorado, Dios. Quienes profesen este tipo de amor evitarán sufrir algunos de los problemas que se muestran en los epígrafes siguientes. Por ejemplo, no sentirán celos ni inseguridades, pues Dios corresponde siempre a quien lo adora y ejerce la suma fidelidad:

Iten, en estos amores bivirás seguro de aver celos; que ya sabes que es inmudable quien tú amas y que siempre te amará tanto como agora y mucho más, si tú quisieres. Y ya sabes tanbién que el amor que te tiene es mayor que el que tú le tienes. Y bien se parece en lo mucho que te da y en lo poco que tú le das. Y quantos más competidores tengas y quanto mejor les fuere a ellos, tanto serás tú más preciado y más amado, porque aquí los unos no impiden a los otros, antes se ayudan en tanto grado que después de Dios no avrá cosa en el mundo que más ames que a tus competidores (238).

Para este amor perfecto no resultan determinantes factores como la edad, que en el De amore funcionaba como un rasgo excluyente: "suelen ser las canas y la vegez estorvo en los otros amores y en éstos no, antes te paras con ellas más hermoso y más dispuesto" (237). Por otro lado, Villalobos sostiene que con este 'buen amor' no existe la posibilidad de enfermar de locura, un aspecto que se analizará en el epígrafe. El amor hacia Dios no radica en el estómago, matriz de los deseos carnales, sino en el propio intelecto. Por ello es, además, más seguro:

Aquí no receles de perder el seso, porque en estos amores ninguna imagen ni fantasma tienes formada ni figurada en la immaginación o fantasía; ca no son amores sensuales éstos, no se conciben em los sentidos, mas son amores intelectuales y puestos en razón [...]. Assí que no enloquecerás ni perderás el juizio en estos amores, porque consisten en la razón y prudencia y son propios amores de hombre en quanto es hombre y no de hombre en quanto es bestia (238).

Como colofón a la larga nómina de beneficios de enamorarse del Creador, Villalobos señala que el vínculo será, además, inmune a las preocupaciones mundanas que ahogan el corazón de los hombres y 
mujeres que establecen relaciones entre ellos. Estas son, por ejemplo, la distancia, elemento en el que el autor encuentra el motivo de grandes locuras cometidas por los varones, como peligrosos viajes hasta acercarse a la amada, duelos y peleas con otros hombres o, incluso, el secuestro de la mujer: "Ni te pueden apartar de quien bien quieres prisiones ni amenazas ni fuerças ni destierro... No ay puerta cerrada para ti cada vez que quieres entrar, porque, en buscando al que amas, le hallarás luego; y en pulsando, luego te abrirán" (237).

Aunque las Sentencias sobre amor es un texto que se caracteriza por su tono sencillo y distendido, la parte moralista de Villalobos aflora cuando aborda las consecuencias de no profesar el amor a Dios que tanto se ha esmerado en presentar y defender:

Si te agradan estos amores, síguelos. Y si no quieres sino muger y dama hermosa y a ésta metella en las entrañas y en los senos del coraçón y que se ande Dios por defuera, como si fuesse una vieja que te ruega y te da quanto tiene, puédeslo hazer. Empuércate bien en tus suziedades... y saldrás tal de allí, que no halla quien de asco pueda mirarte, sino el diablo que te abraçará sin cosa y te meterá en aquella pocilga que tú buscavas. Ella es tal que en pensalla solamente, si bien la contemplas, te tomarán dos mil desmayos (239240).

\section{El amor, ¿una enfermedad?}

Como ya se ha mencionado, que Francisco López de Villalobos fuese un profesional de la medicina aportó un tinte adicional muy valioso en la construcción de su tratado amoroso, si bien es cierto otros textos sobre el mismo tema ya habían manifestado algún tipo de relación entre el universo erótico y la medicina, especialmente en lo tocante con el ánimo y la teoría de los humores ${ }^{6}$. Más allá de la enajenación prototípicamente sentimental, existe un segundo tipo denominado enajenación mental. Esta realidad aparece definida, con la marca de tecnicismo del Derecho — debido a su capacidad de reducir los cargos de una acusación-, por el Diccionario de la RAE como "locura" o "estado mental de quien no es responsable de sus actos; que puede ser permanente o transitorio". Cinco siglos atrás, el doctor Villalobos ya se preguntó por los orígenes de la enajenación mental. Concluyó que el inicio radicaba en lo que él denominó la 'imaginativa', lugar del cerebro donde se construyen las primeras imágenes:

Esta immaginativa adolece algunas vezes de un género de locura que se llama alienación y es por parte de algún malo humor que ofusca y enturbia el espírito donde se hazen las immagines... Assí en la immaginativa por parte del mal humor y por hechura y molde que allí toma, se pueden causar tantas immágines quantas la humana sabiduría no puede comprehender. Y según es la immágen falsa que allí se pone, assí le toma la tema y la alienación a este loco... Y, assí, la immaginativa para pensar distinctamente las cosas es menester que no tenga imagen hecha ni abituada dentro de sí. Porque, si la tiene, es mentirosa y enajenada la imaginación y quanto piensan todo es del metal de aquella imagen que allí está (229-230).

En el caso de los enamorados, aquello que hace degenerar el pensamiento es la imagen de la amada, aquello que para el Capellán era el comienzo del amor, y que está totalmente modificada por las pasiones del sujeto. Desde ahí, el hombre sufre una alteración en su capacidad de percepción de la realidad con la correspondiente creación de una representación falsa en el cerebro. A menudo, la idealización de la dama es de tal magnitud, que necesita de otras fantasías para sostener el engaño. De ahí que la conciencia que el varón tenía acerca del mundo real se altere progresivamente en favor de su fantasía. Es en ese momento cuando puede afirmarse que la enfermedad ya se ha instalado en su cuerpo. Desde ahí, como sucedería en cualquier otro contexto de dolencias médicas, el paciente experimenta diferentes síntomas visibles con los que su organismo pretende dar la voz de alarma.

Para el autor de los Problemas, los indicios manifestados son suficientes para catalogar el amor como una enfermedad. La justificación de esta concepción radica precisamente en la voluntad. Así, es posible considerar que se juzga como enfermo a alguien que, sin quererlo, ha sido atacado por un mal, mientras que el enamorado no se autodefine como víctima de ningún achaque. Del mismo modo, mientras que el

${ }^{6}$ Para un estudio exhaustivo sobre el tema, véanse los trabajos de Caden (1993) y Klibansky et al. (2012). 
enfermo quiere curarse lo antes posible, el enamorado trata de lograr que su dolor se manifieste con mayor intensidad:

\begin{abstract}
De manera que los otros locos querrían sanar y buscan remedios para ello si no es extremada su locura; y éstos no quieren sanar ni lo pueden querer, antes procuran con todas fuerças de meterse más adentro en la pasión y confirmar su dolencia con mayores causas. Esto no lo haze sino que en otras alienaciones sola la imaginación está enajenada, y los enamorados tienen ajena la imaginación y la voluntad con ella. Y con todo esto ha venido en costumbre de la gente que a los otros desvariados llaman locos y a éstos no, sino galanes. Y la causa de su manifiesto error nació y tuvo principio de ver que en los amores cada uno entra por su voluntad propria y por su propio querer. Y assí, a todos ellos paréceles que no es enfermedad la que se toma voluntariamente, sino la que viene por fuerça y violencia de causa que haze enfermar (230-231).
\end{abstract}

La cura de esta debilidad no es sencilla por dos motivos. El primero ya se ha mencionado, no puede curarse lo que no se admite. El segundo se basa en que, aunque el varón reconociese que padece un trastorno mental, no querría ningún remedio para ponerle fin, pues vive feliz en su ilusión. Por lo tanto, la única solución para superar los estragos potenciales del enamoramiento es la separación total de las partes. Asimismo, Villalobos, conocedor de que son pocos los amantes que quieren renunciar a sus sentimientos, propone como otro recurso: alcanzar también la enajenación de la dama para que ella se done al hombre:

\begin{abstract}
La substancial perdición y daño del amador brevemente lo avemos mostrado. El remedio más cierto sería que pusiese tierra y mares entre medias de sí y de su amiga y se encomendase a Dios y a los devotos templos para que le resusciten en su propio ser y le libren daquellas tan ásperas y escuras prisiones. Quando esto no se hiziere,sino que determinadamente ha de seguir por el processo de sus amores, el mayor reparo que tiene es procurar con todas sus fuerças y diligencia que su amada le ame otro tanto como él a ella, porque entonces cada qual dellos dará su voluntad al querer y voluntad del otro, de manera que, juntas y pagadas entrambas voluntades, se haga dellas una voluntad común entr'ellos y cada uno goze de su meitad; y no que quede el uno dellos del todo perdido y deshecho (232).
\end{abstract}

Parte de estos planteamientos pudieron estar marcados por la influencia de los dolcestilnuovistas y su concepción sobre el amor. Esta también guardaba relación con la medicina, especialmente con la relativa al cerebro y a la concepción que tiene el enamorado del mundo: "el objeto del amor es, de hecho, un fantasma... impulsado por la sangre e introducido, como tal, en un círculo neumático en el que se abolen y se confunden las barreras entre lo externo y lo interno, lo corpóreo y lo incorpóreo, el deseo y su objeto" (Serés, 1996: 103). Del mismo modo, esta tradición considera que el posible carácter violento del amante — se volverá sobre ello unas líneas más abajo — se debe, como afirma el propio Villalobos, a la actividad de los diferentes humores y a cómo estos intervienen en las acciones y en los sentimientos de los seres humanos:

\footnotetext{
El extremo delirante ("furioso") de esta circulación espiritual es el amor heroico, que... consiste en una "corruptio imaginationis, debida precisamente a la acumulación de cólera adusta (o sea, un tipo de melancolía) en la cavidad cerebral en que se halla la virtus aestimativa... El corazón tiene que impulsar constantemente espíritus vitales, cuyo calor, unido al del impulso, resesca la cavidad cerebral, lo que produce la melancolía, que no es más que bilis negra, o sea, la bilis amarilla que circula calcinada por el organismo" (Serés, 1996: 103-104).
}

Como parte de esta distorsión de la realidad, es frecuente que aparezcan los celos, situando el problema en un estadio de mayor gravedad. Villalobos establece una estructura dividida en tres partes para desgranar los posibles motivos que conducen a la obsesión celosa. El primer motivo se basa en una relación de causa-efecto prácticamente inalterable: el crecimiento del amor conlleva la aparición de los celos. Si el acto mismo de enamorarse ya implicaba la alteración de las facultades mentales, conforme crece la intensidad del sentimiento, aumentan exponencialmente sus efectos sobre el sujeto. Tampoco en este resulta novedosa la teoría de Villalobos, pues la misma idea de que los celos potencian el amor se recogía ya en el De amore. Allí, además, Andrés el Capellán vincula su origen bien a la pérdida de la amada, bien a un exceso de imaginación por parte del enamorado, anticipándose a lo que luego hará el humanista. 
La segunda razón que da Villalobos para la aparición de los celos es el miedo que siente el varón por perder a su mujer. Frente al tinte sentimental que le otorga el Capellán, Villalobos le concede a este motivo un valor totalmente contrario. El inicio de la actitud celosa no se debe a un sentimiento exagerado de añoranza hacia la mujer, sino a un ejercicio de egoísmo. El amador debe conservar a su amiga junto a él porque en ella ha depositado su voluntad; luego, si esta lo abandona, él quedará sin alma. Dicha preocupación lo lleva a desconfiar de todo cuánto ve, pues encuentra en cualquier escenario motivos para temer su propia perdición. Esto hace que enloquezca todavía más, sufriendo más por lo que imagina que por lo que realmente sucede. Así pues, el amante no siente celos por miedo a perder a su enamorada, sino por sí mismo. Esta concepción rompe la idealización romántica que tradicionalmente reciben los celos por parte de la literatura occidental y que, a su vez, es la que se presenta en el De amore:

Por último, el tercer motivo que explica la aparición del instinto celoso es la ira del enamorado hacia otros hombres que este considere que pueden estar visitando a su señora. Aquí el sujeto se encuentra ya en una fase crítica de enajenación o frenesí. Este frenesí - o "manía" - debe entenderse como una violenta perturbación del ánimo. En esta clase de locura aparece un factor que no se había dado hasta ahora, la agresividad. Por eso, el enamorado celoso se convierte en el prototipo más peligroso de todos los posibles. Es en este tercer punto donde más se alejan las posturas de los autores. Frente a la cruda visión del doctor Villalobos, Andrés el Capellán continúa defendiendo que el amante celoso se enamorada todavía más, incluso cuando tales celos alcanzan su cota máxima, es decir, cuando la mujer se encuentra en posesión de otro hombre, pues el sujeto siente de cerca el peligro de la pérdida y su soledad y, en consecuencia, sus sentimientos por la dama aumentan: "Immo amplius tibi dico: etsi manifeste cognoveris quod alius tuae coamantis fruatur amplexu, magis ex hoc eius incipies affectare solatia" (298).

\section{Los peligros del amor ilícito. Tipos y consecuencias}

Hasta ahora ya se han descrito los peligros de profesar un falso amor que se describen en las Sentencias. Los peligros de este amor, "que no es amor, assí como el oro falso no es oro, aunque lo parece" (224225), se extraen de la relación de beneficios que el médico atribuye al único amor verdadero. Todos los demás tipos, aunque existen variantes ilimitadas, son ilícitos y sensibles al sufrimiento. En primer lugar, el riesgo inmediato de practicar el amor humano es la locura, que puede agravarse conforme se desarrollen los celos en cada uno de los tres estadios descritos. Vinculado a lo anterior, se despertará entre los malos amantes un sentimiento continuo de desconfianza y de miedo a la infidelidad por parte de la otra persona. A la vez, el amor terrenal necesita de cierta proximidad entre los sujetos, pues la lejanía termina por afectar negativamente, bien disminuyendo el sentimiento, bien agravándolo y conduciéndolo a la enfermedad. Además, el falso amor requiere una edad propicia, tanto en cuanto al vigor, como en cuanto a la apariencia física. Villalobos pone el límite en la aparición de las canas. En conclusión, es posible extraer numerosos peligros del mal amor; sin embargo, la mayoría de estas enseñanzas son fruto de la deducción a partir del modelo de amor ideal, pues Villalobos no se centra en desgranar este tipo de amores nocivos, sino que se limita meramente a enunciarlos:

\footnotetext{
Pues el amor nocivo se divide en tantas partes quantos vicios ay y deleites que tú puedes amar, que unos aman la honra, otros la hazienda, otros la gula, otros las mugeres; y assí de todos los otros vicios quantos ay y se pueden pensar. Y porque entre todos los amores viciosos el amor del hombre a la muger y de la muger al hombre es el mayor y más famoso, [...] por éste ligeramente tomarás noticia de los otros amores viciossos que aquí no serán expresados (225).
}

Mayor es el esmero que de Andrés el Capellán, quien detalla con maestría y minuciosidad todos aquellos escenarios que pueden conducir a amores tortuosos. Concluye el primer libro de su De amore con una serie de capítulos que analizan algunos amores bien ilícitos o complicados, que, en definitiva, conducen a la perdición de los amantes o al quebranto del pacto mutuo, es decir, a la infidelidad. El religioso diferencia hasta seis tipos de relaciones poco recomendables. Estos son el amor de los religiosos, el de las monjas, aquel que se obtiene demasiado rápido o por medio del dinero, el de los labradores y, por el último, el amor con prostitutas. 
Si se atiende a la dignidad del individuo, el estado de clérigo es la categoría máxima a la que puede aspirar un hombre, pues este es el estado que se encuentra más próximo a Dios. Seguidamente se encuentran la alta y la baja nobleza y, por último, el tercer estado social (plebeyos). Sin embargo, alcanzar esta dignificación requiere determinados sacrificios, como rechazar todos los placeres carnales y mantenerse alejado de las tentaciones:

Unde manifeste apparet clericum, quantum ad clericalem pertinet claritudinem nobilitatis, amare non posse. Ideoque satis videretur ineptum, si secundum ipsius gradus dignitatem et ordinis nobilitatem de ipsius tractaremus amore. Ab omnibus igitur clericus amoris actibus alienum exsitat, et omnis corporalis immunditia eum relinquat, alias enim sua speciali et a Deo sibi nobilitate largita merito privatus existat (264).

El Capellán confiesa que los religiosos sufren mayores dificultades que el resto de los varones para resistir sus instintos sexuales, pues dice que estos se encuentran en estrecha amistad con ciertas actividades ociosas, como los grandes banquetes, lo que provoca que afloren todo tipo de ardores concupiscentes. Tal es el dolor que el autor considera que soportan los religiosos para aguantar sus ganas de copular que acaba por aconsejar un método para quienes no consigan guardarse. En este caso, deben respetar la jerarquía de clases sociales, de manera que, para saciar su apetito, deberán buscar mujeres que resulten lo más inofensivas posibles al prestigio, es decir, las plebeyas. Al contrario, deben evitarse con especial cautela las mujeres de la alta nobleza y, por descontado, las monjas. El sacerdote que se atreva a yacer con estas no solo se arriesgará a un escándalo mayúsculo, sino que estará contribuyendo a ensuciar el alma de estas mujeres de bien:

\footnotetext{
Quia vix tamen unquam aliquis sine carnis crimine vivit, et clericorum sit vita propter otia multa continua et ciborum abundantiam copiosam prae aliis hominibus universis naturaliter corporis tentationi supposita, si aliquis clericus amoris voluerit subire certamina, iuxta sui sanguinis ordinem sive gradum, sicut superius edocet plenarie de gradibus hominum insinuata doctrina, suo sermone utatur et amoris studeat applicari militiae (264)
}

Como se acaba de señalar, el amor con una religiosa es el estadio mayor de la perversión y, por tanto, se desaconseja por entero. A lo largo de la tradición literaria, los deleites con mujeres del estamento eclesiástico se han presentado como el máximo logro de la seducción. Así ocurre en el mito de don Juan, cuyas artes amatorias son tales, que consigue que la mujer le sea infiel a su marido, Dios. De este modo, como señaló ya Maeztu en aquel célebre ensayo sobre La Celestina, El Quijote y Don Juan de 1926, la conquista de una monja no implica solo divertimiento erótico, se toma como un símbolo de poder y capacidad de desafiar el orden social establecido:

\footnotetext{
Para Ramiro de Maeztu, el impulso sexual masculino representaba la naturaleza indomada. La falta de freno de este instinto libidinoso de los hombres era identificada con el caos civilizatorio y con la ausencia de ideales, ambos rasgos característicos, en su opinión, de aquel momento histórico. La salida que el Don Juan, símbolo del desorden sexual, ofrecía a la incertidumbre reinante era precisamente la "factibilidad de vivir sin otro empeño que los vaivenes de nuestros apetitos y caprichos". La figura del Tenorio representaba para Maeztu el orgullo egoísta y la concupiscencia. Más aún, la pulsión sexual masculina no era sino el empuje barbárico que conducía al desorden social, el temido peligro revolucionario (Aresti, 2018: 14).
}

Por su sentido sacrílego, este tipo de relaciones son las más condenadas por el Capellán: "quia maxima inde coelestis sequitur indignatio patris, et publica inde iura potenter armantur et supplicia minatur extrema, et totius ex hoc crescit in populo mortificativa infamia laudis" (266). El autor - religioso, no se olvide - admite haber tratado de seducir a una monja, por lo tanto, ha practicado el amor inferior. No obstante, y a modo de exemplum, el autor narra cómo logró retirarse antes de firmar su perdición. Esta misma marca autobiográfica puede apreciarse en las Sentencias sobre amor. Villalobos comienza su explicación sobre los diferentes tipos de amores describiendo el amor impuro antes que el verdadero. Más tarde justifica que esta disposición responde a un criterio lógico. El médico admite conocer mejor el amor ilícito porque es el que más ha practicado a lo largo de su vida y, en consecuencia, sobre el que más ha podido aprender: 
Hablaremos primero de las propiedades y passiones del amor vicioso; y después trataremos del amor virtuoso. Y como quiera que en razón de valor y dignidad y tanbién en orden de natura el amor virtuoso precede y es primero que el vicioso, pero en orden de dotrina y para enseñar primero se deve tratar el vicioso, porque dél tenemos más experiencia y mayor noticia, y la orden de la dotrina es que vengamos en conoscimiento de lo que no sabemos por lo que sabemos (225).

Otro punto interesante de este análisis se encuentra en la muestra de individuos que cada autor considera como dignos de practicar el juego del amor. Mientras que para Villalobos cualquier individuo puede aferrarse al verdadero amor y crecer feliz junto a Dios, Andrés el Capellán restringe la actividad solo para cortesanos. Así, los campesinos quedan totalmente excluidos puesto que, considera el religioso, su falta de modales los vuelve más próximos a las bestias que a los hombres. Además, y en consecuencia de lo anterior, son el estamento social que más se deja llevar por las pasiones de la carne, impidiéndoles trabar vínculos más refinados. Sin embargo, en el hipotético caso de que un trabajador de la tierra imite a sus señores y se enamore de una joven, este jamás debe de poder acceder a las técnicas de seducción del amor cortés. El Capellán aborda esta cuestión desde una perspectiva económica. Si el labrador se enrola en juegos de amor, acabará por distraerse, puesto que la distracción es una de las características del enamoramiento, y no cumplirá con los trabajos que tiene a su cargo, por ejemplo, labrar la tierra. Es decir, permitir al campesinado participar en los juegos sentimentales supondría un riesgo para la legitimidad del sistema estamental:

\begin{abstract}
Dicimus enim vix contingere posse quod agricolae in amoris inveniantur curia militare, sed naturaliter sicut equus et mulus ad Veneris promeventur, quemadmodum impetus eis naturae demonstrat. sufficit ergo agricultori labor assiduus et vomeris ligonisque continua sine intermissione solatia. Sed etsi quandoque licet raro contingateos ultra sui naturam amoris aculeo concitari, ipsos tamen in amoris doctrina non expedit erudire ne, dum actibus sibi naturaliter alienin intendunt, humana praedia, illorum solita fructificare labore, cultoris defectu nobis facta infructifera sentiamus (282).
\end{abstract}

En cambio, si cualquier otro hombre perteneciente a un estado superior desease yacer con una campesina, el Capellán desaconseja los cortejos, halagos y demás presentes, algo que deben guardar solo para las dueñas de su rango. Esto se debe a que considera a las labradoras como hembras rudas que no saben del amor. En consecuencia, lo que el autor propone para alcanzar el goce con estas señoras del tercer estado es tomarlas por la fuerza:

\begin{abstract}
Si vero et illarum te feminarum amor forte attraxerit, esa pluribus laudibus effere memento, et, si locum inveneris opportunum, non differas assumere quod petebas et violento potiri amplexu. Vix enim psarum in tantum exterius poteris mitigare rigorem, quod quietos fateantur se tibi concessuras amplexus vel optata patiantur te habre solatia, nisi modicae saltem coactionis medela praecedat ipsarum opportuna pudoris. Haec autem dicimus non quasi rusticanarum mulierum tibi suadere volentes amorem, sed ut, si minus provide ad illas provoceris amandum, brevi possis doctrina cognoscere quis tibi sit processus habendus" (282).
\end{abstract}

A pesar de lo anteriormente dicho, el Capellán aboga por alejarse de aquellos amores "de fácil entrega", es decir, aquellos en los que la mujer le concede demasiado pronto su cuerpo al amante para que goce de él, obviando así todas las fases previas que componen el modelo cortés. Esta clase de mujeres obran así porque tampoco poseen la capacidad de amar. En su caso la explicación se encuentra en el apetito sexual insaciable que les abrasa las entrañas, ardor que les obliga a servirse del vigor masculino para aplacarlo (Montalvo Mareca, 2020: 32-33). En cuanto al varón que tratase de iniciar amores con esta clase de mujeres por los beneficios sexuales que pudiese cosechar con ellas, este sufrirá el dolor de una relación abocada a la infidelidad: "Nam quum propter nimiam Veneris abundantiam huiusmodi mulier nullius se potest amoris vinculis colligare sed multorum appetit libidine satiari, eius frustra quaeris amorem, nisi te in Veneris opera tam potentem agnoveris ut eius valeas libidinem saturare" (278).

Sin embargo, y a pesar de las lecturas que se han hecho del De amore como una obra violentamente machista, el Capellán aborda también la equivalencia de esta fácil entrega en los hombres, en los que señala que también puede darse esa líbido inextinguible: 
Et dicitur esse idem in femina facilis rei petitae concessio quod in homine nimia voluptatis abundatia, quam constat ab amoris aula penitus exsulare. Qui enim tanta carnis voluptate vexatur ut ex cordis affectu nillius se valeat amplexibus colligare, sed quamcunque videt impudico animo concupiscit, hic quidem non amator sed adulterator vocatur amoris ac simulator et erit cane deterior impudico. Immo impetuosus meretur asinus iudicari, quem tanta corporis petulantia movet ut unius possit affectioni astringere. Ergo tibi evidenter apparet quod nimiam voluptatis abundantiam prorsus teneris abiicere et mulieris, in qua facilem petitae rei concessionem cognoveris, amorem tibi non expedit postulare (279-281).

Aquellos hombres que sufrieren de este tipo de comportamiento tampoco son capaces amar, pues no conseguirán desarrollar sentimientos honestos hacia la amada, sino que acabarán por corromperla también a ella. Esta capacidad de empobrecimiento espiritual hace que este prototipo de varón sea una de las figuras que el religioso castiga más severamente en su obra: "Immo impetuosus meretur asinus iudicari, quem tanta corporis petulantia movet tu unius se non possit affectioni astringere" (280).

Del mismo modo, De Amore invita a desconfiar siempre de las mujeres avariciosas y de aquellas que permiten el amor como medio para conseguir dinero o regalos materiales, pues tampoco se trata de un sentimiento verdadero: "Sed si aliqua mulier avaritiae tanto detineatur ardore ut muneris gratia se ipsam largiatur amanti, haec a nemine reputetur amatrix sed falsificatrix amoris et immundarum mulierum prostibulis adiungenda" (270). Así, Andrés el Capellán, juzga la codicia y la presunción como dos rasgos de naturaleza constante en la caracterización femenina. Con ello, se enmarca en la tradición misógina medieval, después heredada en los siglos XVI y XVII sin apenas sustanciales a pesar de las nuevas tesis humanistas y renacentistas, que consideraba a las mujeres seres inferiores a los hombres y con una serie de vicios innatos que empobrecía sus almas: "Juntóse con el ser raro la delicadeza del artificio, y de allí nasció el precio, y del precio la mala codicia que dello las mugeres tienen, las quales se pierden por lo precioso y costoso" (León, 2002: 165). Puesto que su natural es profesar un gusto exagerado por el dinero, las mujeres deben guardarse de este impulso para poder acceder al amor, de lo contrario será difícil fácil encontrar un ejemplo donde la dama estime más al marido que los bienes de este.

Una vez ha terminado de describir este tipo de comportamientos femeninos, el religioso comienza con los consejos para los hombres que quieran tratar con ellas. En primer lugar, antes de iniciar los amores deberán cerciorarse de que la dama les guardará fidelidad también en la pobreza, puesto que todas la conservan en los periodos de bonanza económica. Asimismo, el varón deberá contemplar que estas señoras, con frecuencia, fingen amar al hombre solo para recibir mil regalos, hasta terminar por arruinarlo por completo. Entonces, cuando el enamorado ya no dispone de más dinero o patrimonio, airadas por la falta de bienes, abandonan su personalidad impostada y se muestran como son: viles e interesadas. Frente a esto, el Capellán sentencia que la mujer que ama verdaderamente siente rechazo por los obsequios, pues no quiere ver disminuido el patrimonio que pasará a ser de ambos.

Para concluir este paseo por los amores ilícitos, Andrés el Capellán recomienda a los varones que, si sufren episodios en los que su deseo sexual es demasiado acusado, no se expongan a la posibilidad de topar con una mujer de las que ha descrito. En consecuencia, anima a la contratación de prostitutas, pues el daño económico y el espiritual será siempre menor al que pueda provocar una mala dama: "Si enim tanta corporis te petulantia cogat, ut soldatas quaerere velis feminas, magis tibi expedit cum mulieribus publice in prostibulo commorantibus negotiari et earum pretio corpus parvo mercari, quam sub amoris figmento ab aliqua se dominam simulante meretricio more velle propriis exspoliari divitiis" (276). Con todo, resulta extraño el somero tratamiento que da el autor al amor de las prostitutas. Si bien en el resto de los casos ha explicado, a veces desde la experiencia, cómo lograr satisfacer los deseos con determinados colectivos, sobre este tipo de relaciones se muestra excesivamente parco. Esto pudo deberse a que el ambiente prostibulario, a priori, quedaría fuera de los círculos a los que tenía acceso el religioso y que, por lo tanto, lo desconocía en gran medida. Por otro lado, y dado que ya había descrito antes los amores con mujeres que se entregan demasiado rápido o con otras que solo se sirven del amor como un método para conseguir dinero, huelgue de repetir la explicación. 


\section{Conclusión}

Como resultado de este trabajo, es posible extraer una perspectiva híbrida del amor basada en dos perspectivas: la de un religioso, a través del De amore de Andrés el Capellán, y la de un médico, por medio del estudio de las Sentencias sobre amor de Francisco López de Villalobos. La separación en el tiempo de las obras (De amore, ca. 1185 y Sentencias, 1554) permite mostrar en un eje temporal la fijación del concepto del amor cortés a lo largo de los últimos siglos de la Edad Media y los primeros años del Renacimiento español, así como sus principales cambios e influencias. Además, a lo largo de estas páginas también se ha tratado uno de los conceptos más importantes del amor, que llega, incluso, a nuestros días, motivado por la proliferación de los estudios psiquiátricos y psicoanalistas: la condición del amor entendido como una enfermedad del cerebro que anula la voluntad de los individuos y los convierte en seres impulsivos e impredecibles, en ocasiones, incluso en sujetos potencialmente peligrosos.

Tras la comparación de ambos testimonios, se advierte que los puntos en común son mayores que los desacuerdos. Los aspectos parejos entre ambos autores van desde la forma de organizar el texto hasta sus temas y subtemas, pasando también por las fuentes para la elaboración del pensamiento. Respecto a los criterios formales, en ambos está presente el carácter experiencial durante la narración; los autores admiten haber accedido a algunos de los amores que luego clasificarán como ilícitos, hecho que sorprende más en el caso del clérigo por su vinculación a la Iglesia. Otro aspecto parejo en ambos tratados es la vinculación del concepto de amor a la sexualidad, si bien es cierto que en las Sentencias esta relación se da solo para el falso amor. Los autores justifican el comportamiento del hombre como un vehículo para conseguir el premio otorgado por la dama, es decir, el consentimiento para yacer con ella. Paralelamente, uno y otro se ocupan de caracterizar el sexo como el núcleo del pecado, pues es este ardor desmedido lo que hace que, tanto hombres como mujeres, alcancen la enajenación, llevándolos a actuar contra la moral, la religión e incluso en contra de las leyes jurídicas (asesinato por celos, incesto, violación de las reglas monacales...). Frente a este mal amor, Andrés el Capellán y el doctor Villalobos describen un amor verdadero que es capaz de engrandecer y perfeccionar a quienes lo practican. El Capellán lo enfoca desde una perspectiva aristotélica, de acuerdo con la teoría del alma intelectiva, mientras que Villalobos lo reduce al amor a Dios; es decir, las dos visiones tratan de alejarlo de los terrenal para elevarlo al estado más alto.

En último lugar, en el epígrafe final se recogen algunos de los amores más conflictivos tal y como los presentan los autores de sendos tratados. Si bien su contenido no supone el grueso de este trabajo, sí que posee un interés relevante para los estudios humanísticos, especialmente para los que versan sobre literatura y filosofía, ya que en él aparecen expuestas algunas ideas cruciales que, con el paso de los siglos, irán desarrollándose hasta quedar fijadas como una parte indivisible de la historia de la literatura y del pensamiento europeo. Se trata, por ejemplo, del personaje de la monja seducida y el modelo del seductor (Don Juan Tenorio), el religioso lascivo (Libro de Buen Amor), las prostitutas y sus relaciones (La Celestina) o la caracterización peyorativa de la mujer presente en gran parte de la literatura de matrimonio, género de enorme popular en los siglos XVI y XVII.

\section{Referencias bibliográficas}

Aresti, N. (2018). "La peligrosa naturaleza de Don Juan. Sexualidad masculina y orden social en la España de entreguerras”. Cuadernos de Historia Contemporánea. 40. 13-31.

Aristóteles (2014). De anima. Traducción de T. Calvo Martínez. Gredos. Madrid.

Arrizabalaga, J. (2002). "Francisco López de Villalobos (c.1473-c.1549), médico cortesano". Dynamis. 22. 29-58.

Baranda Leturio, C. (2014). "El humanismo frustrado de Francisco López de Villalobos y la polémica con Hernán Núñez”. eHumanista. 29. 208-239. 
Basarte, A. (2012). Nueve ensayos sobre el amor y la cortesía en la Edad Media. Editorial de la Facultad de Filosofía y de Letras de la Universidad de Buenos Aires. Buenos Aires.

Cabello Pino, M. (2012). "La corriente científico-filosófica de la enfermedad de amor en la Grecia Clásica: Hipócrates, Platón y Aristóteles”. Analecta Malacitana Electrónica. 33. 29-43.

Caden, J. (1993). Meaning of sex difference in the Middle Ages: Medicine, Science and Culture. Cambridge University Press. Cambridge.

Capellanus, A. (1982). Andreas Capellanus. On love. Edición de P. G. Walsh. DuckWorth. Londres.

Capellanus, A. (1985). De amore. (Español-Latín medieval) Edición bilingüe español-latín medieval de I. Creixell Vidal-Quadras. Edicions del Quaderns Crema. Barcelona.

Capellanus, A. (2006). Libro del amor cortés. Edición de P. Rodríguez. Alianza. Madrid.

Duby, G. (1994). "El modelo cortés" en Historia de las mujeres en Occidente, t. II. Taurus. Madrid. 301-320.

Fabié y Escudero, A. Ma . (1886a). Vida y escritos de Francisco López de Villalobos. Imprenta de Miguel Ginesta. Madrid.

Fabié y Escudero, A. Mª (1886b). Algunas obras el doctor Francisco López de Villalobos. Imprenta de Miguel Ginesta. Madrid.

Gilalbert Barberà: (1996), "Tradición misógina griega en el De amore de Andrés el Capellán” en Actes del Simposi Internacional de Filosofia de l'Edat Mtjana. El pensament antropològic medieval en els àmbits islàmic, hebreu i cristià. Patronat d'Estudis Osonencs. Vic. 550-558.

Klibansky, R. et al. (2012). Saturno y la melancolía: estudios de historia de la filosofía de la naturaleza, la religión y el arte. Traducción de M. L. Balseiro. Alianza. Madrid.

Jaramillo Antillón, J. (2001). ¿El sexo débil de la mujer? Editorial de la Universidad de Costa Rica. San José.

León, L. de (2002). La perfecta casada. Edición de J. San José Lera. Espasa-Calpe. Barcelona.

López de Villalobos, F. (2001). "Sentencias sobre amor" en Tratados de amor en el entorno de Celestina (siglos XV-XVI). Edición de P. M. Cátedra. Sociedad Estatal España Nuevo Milenio. Madrid.

López Paredes, O. E. y Orellana, M. (2013). "Los celos desde un punto de vista psiquiátrico". Revista Hondureña del Postgrado en Psiquiatría. 7. 21-36.

Maeztu, R. de (1926). Don Quijote, Don Juan y la Celestina: ensayos de simpatía. Calpe. Madrid.

Martínez Sáez, N. (2020). “Ovidio como fuente principal en el De amore de Andrés el Capellán”. Revista Chilena de Estudios Medievales. 17. 67-72.

Montalvo Mareca, S. (2020). "Amor y sexualidad en la Baja Edad Media: una mirada a través del De amore de Andrés el Capellán”. Ímpetu. 3. 19-37.

Paris, G. (1883). “Le Conte de la Charrette”. Romania. 12. 459-534.

Parker, A. (1986). La filosofía del amor en la literatura española: 1480-1690. Cátedra. Madrid.

Real Academia Española (2014). Diccionario de la lengua española. Espasa. Madrid. 
Rodazo Ruiz, A. M. (2000). "Tristura conmigo va”. Fundamentos de amor cortés. Universidad de Castilla-La Mancha. Cuenca.

Rojo Vega, A. (1993). "Francisco López de Villalobos, médico real (1473-1549)". Brigecio: Revista de estudios de Benavente y sus tierras. 3. 175-186.

Sánchez Granjel, L. (1979). Vida y obra de López de Villalobos. Ediciones Universidad de Salamanca. Salamanca.

Sarrión Mora, A (1994). Sexualidad y confesión: la solicitación ante el Tribunal del Santo Oficio (siglos XVI-XIX). Alianza. Madrid.

Serés, G. (1996). La transformación de los amantes. Crítica. Barcelona.

Sevilla, I. de (2009). Etimologías. Edición de J. Oroz Reta y M. A. Marcos Casquero. Biblioteca de Autores Cristianos. Madrid. 